$17 \dagger$ These authors contributed equally to this work

18 §Currently at Amyris Biotechnologies, Emeryville, CA, USA

19 *Corresponding author

20 Dr. Anup K Singh

21 Sandia National Laboratories

22 P.O. Box 969, Mail Stop 9291

23 Livermore, CA 94551-0969

24 Email: aksingh@sandia.gov

25 Phone: 925-294-1260

\title{
Post-translational Modifications of Desulfovibrio vulgaris Hildenborough Sulfate Reduction Pathway Proteins.
}




\section{ABSTRACT}

2 Recent developments in shotgun proteomics have enabled high-throughput studies of

3 a variety of microorganisms at a proteome level and provide experimental validation for

4 predicted open reading frames in the corresponding genome. More importantly, advances

5 in mass spectrometric data analysis now allow mining of large proteomics datasets for the

6 presence of post translational modifications (PTMs). Although PTMs are a critical aspect

7 of cellular activity, such information eludes cell wide studies conducted at the transcript

8 level. Here we analyze several mass spectrometric datasets acquired using two

9 dimensional liquid chromatography tandem mass spectrometry, 2D-LC/MS/MS, for the

10 sulfate reducing bacterium, Desulfovibrio vulgaris Hildenborough. Our searches of the

11 raw spectra led us to discover several post translationally modified peptides in $D$.

12 vulgaris. Of these, several peptides containing a lysine with a +42 Dalton (Da)

13 modification were found reproducibly across all datasets. Both acetylation and

14 trimethylation have the same nominal +42 Da mass, and are therefore candidates for this

15 modification. Several spectra were identified having markers for trimethylation, while

16 one is consistent with an acetylation. Surprisingly, these modified peptides predominantly

17 mapped to proteins involved in sulfate respiration. Other highly expressed proteins in $D$.

18 vulgaris, such as enzymes involved in electron transport and other central metabolic

19 processes, did not contain this modification. Decoy database searches were used to

20 control for random spectrum/sequence matches. Additional validation for these

21 modifications was provided by alternate workflows, for example, two-dimensional gel

22 electrophoresis followed by mass spectrometry analysis of the dissimilatory sulfite

23 reductase $\gamma$-subunit (DsrC) protein. MS data for DsrC in this alternate workflow also

24 contained the +42 Da modification at the same loci. Furthermore, the DsrC homolog in

25 another sulfate reducing bacterium, D. desulfuricans G20, also showed similar $+42 \mathrm{Da}$

26 modifications in the same pathway. Here we discuss our methods and implications of

27 potential trimethylation in the $D$. vulgaris sulfate reduction pathway.

30 Key words: iTRAQ, SRB, DsrC, trimethyl-lysine, acetylation, PTMs 


\section{INTRODUCTION}

2 Desulfovibrio vulgaris Hildenborough belongs to the sulfate reducing class of

3 bacteria (SRB). Recently, interest in the physiology of $D$. vulgaris has been heightened

4 due to its potential in bioremediation applications at toxic and radioactive metal

5 contaminated sites. Before bioremediation strategies can be implemented effectively,

6 however, cellular models must be developed that capture the complex relationships

7 between the environment and the desired metabolic activity. Techniques such as genome

8 sequencing and transcriptomics were developed as a first step toward such

9 comprehensive cellular analysis. Yet, following extensive study, it was determined that,

10 while these techniques formed an important foundation, much of cellular behavior

11 remained unexplained. Technological and analytical advances in mass spectrometry-

12 based protein studies have resulted in high-throughput analyses of a variety of

13 microorganisms at a proteomic level ${ }^{1-6}$, with shotgun proteomics emerging as a popular

14 and powerful method ${ }^{7,8}$. Consequently vast amounts of mass spectroscopic data are now

15 available that can be mined to obtain many different types of information about the

16 source organisms. The use of rigorous data analysis methods allows for highly accurate

17 high-throughput identification of peptides. At the most fundamental level, these studies

18 provide valuable experimental validation for the presence of the predicted proteins. A

19 critical feature inherently contained in these datasets that eludes other cell-wide profiling

20 methods is post translational modifications (PTMs).

21 Proteomics studies have formed an important part of the several cell-wide studies

22 focused on understanding cellular response in the anaerobic organism D. vulgaris to a

23 variety of growth conditions ${ }^{3,9-11}$. Utilizing the iTRAQ workflow and 2D-LC/MS/MS, a

24 large number of shotgun proteomics datasets were collected. Using these datasets,

25 Mascot MS/MS Ion searches, including decoy database searches, were conducted to

26 identify potential PTMs in D. vulgaris. Recently, a number of similar studies have been

27 reported in other organisms ${ }^{12-14}$. Many PTMs are known to play critical roles in bacterial

28 regulation. Methylations are known to be involved in bacterial signal transduction,

29 especially in chemotaxis systems ${ }^{15}$, but have also been shown to be involved in protein

30 translation $^{16,17}$. Acetylations in bacterial systems have been shown to regulate enzyme

31 function $^{18}$ as well as participate in signal transduction ${ }^{19}$. Recent studies of acetylation in 
1 eukaryotic systems have revealed many acetylation sites beyond those present in

2 histones, suggesting that they play a role in many key metabolic functions ${ }^{20,21}$. N-

3 terminal protein modification has been shown to be involved in protein maturation and

4 has been implicated in controlling protein half-life ${ }^{22}$. Additionally, oxidation of histidine

5 residues has been shown to be a mechanism for providing transcriptional control ${ }^{23}$.

6 Despite the fact that phosphorylations are known to be important in signal transduction

7 mechanisms $^{24}$ and stasis ${ }^{25}$, they are chemically labile and do not lend themselves to

8 detection following the sample handling techniques utilized. Likewise, glycosylations

9 and lipid modifications are less abundant in prokaryotes, but have been identified in

10 various species and cause a variety of cellular effects ${ }^{26,27}$. However, these modifications

11 require specific isolation methods to be studied. All of these modifications have been

12 found ubiquitously in all organisms, not only bacteria, and have been shown to have

13 varied and diverse functions in protein activity and regulation ${ }^{28-33}$. Thirty-five amino

14 acid modifications were selected for inspection in this study. One primary focus was the

15 investigation of amino acid oxidations, given that two of the four samples had undergone

16 oxidative stress. Protein methylation, acetylation, and N-terminal modifications were

17 targeted for study because they are among the most commonly found ${ }^{17,34}$, chemically

18 stable modifications and are known to be involved in biologically relevant phenomena.

19 Additionally, in vitro modifications or adducts were examined to investigate the role of

20 sample preparation in protein modification events. Many modifications expected to be

21 chemically labile, present in low abundance, or requiring specific isolation methods were

22 not considered here. The methods used to search the proteomics datasets of D. vulgaris

23 for PTMs are outlined. Further, validation of these results was provided by conducting

24 decoy searches and by mining orthologous datasets acquired using different workflows.

25 Interestingly, many PTMs were discovered in the sulfate reduction pathway, and the

26 implications of these modifications are discussed.

METHODS

29 Biomass production. Desulfovibrio vulgaris Hildenborough (ATCC 29579) was

30 grown in a defined lactate $(60 \mathrm{mM}) /$ sulfate $(50 \mathrm{mM})$ medium, $\mathrm{LS} 4 \mathrm{D}^{9}$, under a variety of

31 different stress treatments or growth conditions. To minimize sub-culturing during 
1 experimentation, $D$. vulgaris stocks stored at $-80^{\circ} \mathrm{C}$ were used as a $10 \%(\%$ is v/v unless

2 otherwise indicated) inoculum into $100-200 \mathrm{~mL}$ of fresh LS4D medium to produce starter

3 cultures, and the cells were grown to mid-log phase $\left(\mathrm{OD}_{600} 0.3-0.4\right)$. Fresh starter

4 cultures were used as 10\% inoculum into 1-3 L biomass production cultures and grown at

$530^{\circ} \mathrm{C}$. All production cultures were grown in triplicate. In each condition, both control

6 and stress treated cultures were grown. Cells were allowed to grow to an optical density

7 of approximately 0.3 prior to application of the treatment condition. The treatments were

8 as follows: $250 \mathrm{mM}$ nitrate for 8 hours $^{11}$ (Dataset 1), $0.1 \%$ oxygen exposure for 4 hours ${ }^{35}$

9 (Dataset 2), and air stress at both 2 and 4 hours ${ }^{35}$ (Dataset 3). Control cultures were

10 treated with an equivalent volume of water (Dataset 1) or bubbled with prepurified

11 nitrogen (Datasets 2 and 3). Biomass collection occurred immediately following the

12 specified treatment time, and sample processing and chilling times for biomass collection

13 were minimized by pumping samples through a metal coil immersed in an ice bath as

14 described previously ${ }^{9,}$. The chilled samples were harvested via centrifugation, flash

15 frozen in liquid nitrogen, and stored at $-80^{\circ} \mathrm{C}$ until analysis. Additionally, a D. vulgaris

16 sample grown for 96 hours under conditions promoting biofilm formation was compared

17 to a 96-hour culture employing standard planktonic growth conditions, and proteomics

18 data obtained from this sample (Dataset 4) was also used (Clark and Redding,

19 unpublished data). No additional stress treatment was applied to this biofilm sample.

20 Proteomics sample preparation and data acquisition. Sample preparation,

21 chromatography, and mass spectrometry for iTRAQ proteomics were performed as

22 described previously ${ }^{11}$. Briefly, frozen cell pellets from triplicate $50 \mathrm{~mL}$ cultures were

23 thawed and pooled prior to cell lysis. Cells were lysed via sonication in lysis buffer,

24 composed of $4 \mathrm{M}$ urea with $500 \mathrm{mM}$ triethylammonium bicarbonate (TEAB), $\mathrm{pH} 8.5$

25 (Sigma-Aldrich), and the clarified lysate was used as total cellular protein. Sample

26 denaturation, reduction, blocking, digestion, and labeling with isobaric reagents were

27 performed according to the manufacturer's directions (Applied Biosystems, Framingham,

28 MA). For the nitrate stress experiment (Dataset 1), $150 \mu \mathrm{g}$ of protein was labeled with 3

29 separate labeling reagent vials, whereas $80 \mu \mathrm{g}$ of protein were labeled with a single

30 reagent vial for all other samples. Strong cation exchange (SCX) chromatography was

31 used to separate the iTRAQ-labeled samples into 21-23 salt fractions. Fractions were 
1 desalted using $\mathrm{C}_{18}$ MacroSpin Columns (Nest Group, Southborough, MA), dried, and

2 separated on a PepMap100 $\mathrm{C}_{18}$ reverse phase nano-LC-MS column (Dionex-LC

3 Packings, Sunnyvale, CA) using an Ultimate HPLC with Famous Autosampler and

4 Switchos Micro Column Switching Module coupled with an ESI-QTOF mass analyzer

5 (QSTAR® Hybrid Quadrupole TOF, Applied Biosystems) as previously described ${ }^{11}$. A

6 2-hour gradient from 0-25\% acetonitrile was used. Two product ion scans were collected

7 for each cycle with a 1-s accumulation time. A threshold of 50 counts was required for

8 ions to be selected for fragmentation. Parent ions and their isotopes were excluded from

9 further selection for 1 minute, with a mass tolerance of $100 \mathrm{ppm}$. Typical mass accuracy

10 achieved for these data sets was $50 \mathrm{ppm}$, thus peptide modification by acetylation versus

11 trimethylation (discussed below), a difference of $0.036 \mathrm{Da}$, could not be distinguished

12 based on mass measurement alone.

13 MS/MS dataset analysis. The data mining approach is shown in Figure 1. Peak lists

$14(\mathrm{~m} / \mathrm{z}$ vs. intensity) were generated for the resulting spectra from every individual

15 LC/MS/MS file using the Distiller program (version 2.1, Matrix Science Inc, Boston,

16 MA), with parameters given in Supplementary Table 1. Peak lists from individual files

17 were then merged for each stress condition to form Datasets 1, 2, 3 and 4, which were

18 used for all subsequent analysis. The only exception was Dataset 3, where two of the

19 LC/MS/MS files (strong cation exchange fractions 7 and 10) contained scans with no

20 data, rendering the Distiller program unable to handle these files without manual

21 intervention. Consequently, these two files were omitted from the analysis. A protein

22 search database was generated from a FASTA file containing all the putative ORF

23 sequences of $D$. vulgaris (obtained from microbesonline.org ${ }^{36}$, 2005-02-08 upload, 3632

24 genes) appended with trypsin, bovine serum albumin, and ovalbumin. Identical search

25 parameters were used in all cases, which were as follows: tryptic peptides with up to 1

26 missed cleavage site were considered, the precursor ion $\mathrm{m} / \mathrm{z}$ tolerance was set at $+/-200$

$27 \mathrm{ppm}$, and the product ion $\mathrm{m} / \mathrm{z}$ tolerance was set at $+/-0.2 \mathrm{Da}$. Modifications were

28 considered either as static (where all occurrences of the given amino acid are expected to

29 be modified, e.g., chemical alkylation of cysteine) or variable (where the given amino

30 acid may be present in both modified and unmodified forms, e.g., oxidation of

31 methionine). The choice of static and variable modifications varied according to the 
1 search conducted. The datasets were submitted initially to a preliminary Mascot search

2 against the $D$. vulgaris protein database. The preliminary search allowed for

3 modification of primary amines by the iTRAQ reagent (lysine residues and peptide $\mathrm{N}$ -

4 terminus) and alkylation of cysteines (methyl methane thiosulfonate for Datasets 1 and 2,

5 and carbamidomethylation for Datasets 3 and 4) as static modifications. Both methionine

6 oxidation to sulfoxide and iTRAQ labeling of $\mathrm{Y}$ were also allowed as variable

7 modifications. Further searches used the same criteria with the following exceptions:

8 where additional possible modifications on $\mathrm{K}, \mathrm{C}$, or protein $\mathrm{N}$-terminal residues were

9 allowed, iTRAQ labeling and alkylation were considered as variable modifications;

10 additional modifications were considered as variable modification in individual searches

11 as specified (Supplementary Table 2).

12 Potential amino acid modifications were identified from literature and on the web at

13 unimod.org, ionsource.com, and abrf.org (Delta Mass database). In all, 35 modifications

14 were selected for analysis. As Dataset 1 represented the most comprehensive analysis in

15 terms of the number of proteins identified and spectra collected, MS/MS peak lists from

16 Dataset 1 were submitted to Mascot in 22 additional searches with discrete PTMs of

17 interest specified. Structures of the considered modifications are shown in

18 Supplementary Figure 1, with accompanying parameters listed in Supplementary Table 2.

19 Results (peptide sequences, modifications, match scores, etc) were exported to Excel,

20 where sequences were filtered to retain only the top scoring match for each spectrum with

21 an expectation value $\leq 0.05$. This corresponds to a match score at the $95 \%$ confidence

22 interval of the Mascot scoring scheme for a given search. Searches with and without

23 additional modifications specified (searches 1 and 11, Supplementary Table 2) were also

24 performed against a reversed sequence database generated from the D. vulgaris database

25 to confirm that this score cutoff yielded an acceptable false discovery rate. Where

26 multiple equivalently scoring matches from a given spectrum exceeded this threshold, the

27 match with the highest protein score was retained. In cases where a given modification

28 may occur at more than one location within the matched peptide sequence, only the

29 highest scoring isomer is reported. The numbers of peptides from Dataset 1 having each

30 amino acid modification and passing the filter criteria were counted, and the results are 
1 shown in Table 1. A list of all modified peptide sequences indicated in Table 1 is given 2 in Supplementary Table 3.

3 The modifications were further classified to distinguish between likely biological

4 modifications (in vivo) as compared to those likely caused by sample handling (in vitro).

5 In vivo modifications that returned the greatest number of peptides were identified as

6 "target modifications", which were $\mathrm{P}(+18), \mathrm{K}(+28), \mathrm{D} / \mathrm{E}(+14), \mathrm{K}(+42)$, as well as N-

7 terminal modifications of methylation, formylation, and acetylation, and initial

8 methionine cleavage. Peak lists from the other three Datasets were then subjected

9 separately to Mascot searches with the target modifications specified. Resulting peptides

10 having the target modifications were exported to Excel and filtered as for Dataset 1. The

11 numbers of peptides having each amino acid modification and passing the filter criteria

12 were counted, and the results are shown in Table 2. A list of all modified peptide

13 sequences indicated in Table 2 is given in Supplementary Table 4. Raw spectra were

14 extracted from Dataset 1 for the peptides containing a $\mathrm{K}(+42)$ modification identified in

15 at least two samples, and the sequence assignments were manually validated.

16 Peptides that passed the filtering criteria (top scoring match, expectation value $\leq 0.05$ )

17 and were identified as protein $\mathrm{N}$-terminal sequences for each dataset are listed in

18 Supplementary Table 5. The number of each category of N-terminal modification was

19 counted and is listed in Supplementary Table 6.

\section{RESULTS}

22 Amino acid modifications - post translational (in vivo) vs. artifacts (in vitro). This

23 study used four 2D-LC/MS/MS iTRAQ proteomics datasets acquired as part of previous

24 studies for $D$. vulgaris. The initial Mascot survey of the four datasets indicated that

25 Dataset 1 was the most comprehensive in terms of number of spectra acquired and total

26 proteins identified. Therefore, this dataset was used as the benchmark to evaluate the

27 extent of known side reactions and other experimental artifacts, in addition to providing a

28 first pass for profiling predominant modifications. The complete list of the 35 amino acid

29 modifications considered (excluding protein $\mathrm{N}$-terminal modifications), and the total

30 number of unique sequences that passed the filtering thresholds from Dataset 1 is

31 reported in Table 1. As shown, 6175 peptides were identified in Dataset 1 containing 
1 only the expected modifications of K- and peptide N-terminal iTRAQ labeling, which

2 represents about $18 \%$ of the 33,477 submitted queries. It is known that the iTRAQ

3 reactive group, comprised of an NHS-ester, may also have a side reaction with tyrosine

4 residues. Approximately 5\% of the peptides returned were identified to have an iTRAQ-

5 labeled $\mathrm{Y}$, which is slightly higher than previously reported ${ }^{37}$. Prior to evaluating

6 potential PTMs, it is critical that potential labeling side reactions and the efficiency of all

7 sample preparation reactions be examined to ensure that the appropriate modifications are

8 included in the search space without needlessly increasing it. This is important as

9 increases in search space lead to increases in the threshold required to pass the filtering

10 criteria, which may mask the presence of actual PTMs.

11 To evaluate the labeling efficiency of peptide primary amines (lysines and N-

12 terminus), a separate Mascot search was performed, in which iTRAQ labeling of $\mathrm{K}$ or $\mathrm{N}$ -

13 terminus was allowed to be variable. In this search, a total of 6220 unique peptide

14 sequences passed the filtering thresholds. Of these, $309(\sim 5 \%)$ were identified as having

15 an unlabeled peptide $\mathrm{N}$-terminus. A total of 2665 sequences contained one or more

16 lysines, and of these, only $14(\sim 0.5 \%)$ were identified as having unlabeled $\mathrm{K}$. The overall

17 trend observed is that iTRAQ labeling is highly efficient for $\mathrm{K}$ side chains, but peptide $\mathrm{N}$ -

18 termini are slightly less reactive. This observation is important for further spectrum

19 interpretation, as will be shown. Labeling of $\mathrm{S}$ or T by iTRAQ was negligible, as

20 expected. No iTRAQ labeling of $\mathrm{C}$ was observed, which was consistent with the fact that

21 the $\mathrm{C}$ residues are always reduced and blocked prior to labeling. The efficiency of

22 cysteine modification was evaluated by performing a search allowing for variable methyl

23 methane thiosulfonate (MMTS) modification of cysteine. In this case, only 7 peptides

24 were returned having unmodified cysteines, indicating that alkylation had indeed

25 proceeded to completion.

26 Several amino acid modifications that are most likely experimental artifacts (but

27 cannot be completely ruled out as post-translational) were observed in Dataset 1; these

28 include pyroglutamine formation from $\mathrm{N}$-terminal $\mathrm{Q}$ (76 peptides), deamidation of $\mathrm{N}$ or

29 Q (443 peptides total), and oxidation of $\mathrm{M}$ to methionine sulfoxide (118 peptides).

30 Pyroglutamine formation is promoted by acidic conditions and likely occurred during the

31 chromatography steps, which were performed at a $\mathrm{pH}$ of 3. Deamidation of $\mathrm{N}$ and $\mathrm{Q}$ is 
1 known to occur at physiological $\mathrm{pH}$, consequently deamidation could have occurred in

2 vivo or in vitro. Interestingly, there appears to be a preference for deamidation of N (345

3 peptides) versus $\mathrm{Q}$ (98 peptides), which has been reported previously ${ }^{38}$. It is also possible

4 that the deamidation observed was due to an experimental artifact where the ${ }^{13} \mathrm{C}$ peak was

5 incorrectly selected for MS/MS analysis. However, this does not explain the observed

6 preference for a +1 Da mass shift on $\mathrm{N}$-containing peptides - an equivalent number of $\mathrm{N}$

7 and Q amino acids are present in the identified sequences, which should have produced a

8 comparable number of $\mathrm{N}$-and Q-containing peptides if the ${ }^{13} \mathrm{C}$ peak was selected for

9 analysis. Methionine oxidation to methionine sulfoxide is known to occur during sample

10 handling and storage; however, it can also occur in vivo ${ }^{39}$.

11 Peptides identified with these modifications were then examined to determine if

12 modified peptides tended to occur along with the unmodified counterpart. Artifacts of

13 iTRAQ modified tyrosine and methionine sulfoxide were generally observed along with

14 an unmodified counterpart, while this was not the case for pyroglutamine and

15 deamidation modified peptides. In total, peptide sequences with such chemical

16 modifications represent more than $10 \%$ of the sample. Because additional modifications

17 were not considered in the current search set, the total fraction of in vitro modified

18 peptides in this sample may be higher. Such a study highlights the importance of

19 minimizing chemical side reactions so that the biological modifications are not masked.

20 Many modifications, such as methylations and certain oxidations/hydroxylations,

21 are more likely to be post translational modifications rather than in vitro side-reactions.

22 The most extensive of these reactions identified in Dataset 1 were hydroxyproline (34

23 peptides), methylated D/E (69 peptides), dimethylated K (21 peptides), and a +42 Da

24 modification on $\mathrm{K}$ (18 peptides) (Table 1). The $+42 \mathrm{Da}$ modification is consistent with

25 either acetylation or trimethylation, as they have the same nominal mass. It should also be

26 noted that although the search for methylation of $\mathrm{N}$ and $\mathrm{Q}$ residues returned 23 peptides,

27 on a per residue basis this is estimated to be only approximately 12 identifications (i.e.,

2823 matches divided by 2 amino acids). As is evident, the total number of modified

29 peptides having biologically relevant modifications is far fewer compared to side-

30 reactions. Following the identification of the most prevalent modifications in Dataset 1 ,

31 the remaining three datasets were examined for these modifications (Table 2). 
In addition, the $\mathrm{N}$-terminal characteristics of the peptides in all four datasets were

2 examined to assess if the initial methionine was intact and if the terminus was methylated, formylated, or acetylated. Overall, approximately $50 \%$ of the detected

4 protein $\mathrm{N}$-termini were identified having the initial methionine cleaved (Supplementary

5 Table 6). Very few matches were returned with additional modifications, indicating that

6 further protein N-terminal modification does not appear to be extensive in D. vulgaris.

8 Assessment of PTM assignment accuracy. While the probabilistic scoring functions

9 built into search algorithms such as Mascot or SEQUEST aid the user in eliminating

10 random sequence matches, a certain statistical percentage of false positive identifications

11 are made and a certain percentage of spectra are discarded as false negatives. A Mascot

12 expectation value of $\mathrm{p} \leq 0.05$ was utilized as the cutoff threshold for accepting peptide

13 results to minimize false positive results. Additionally, several reverse database searches

14 were performed to estimate the resultant false positive rate. Specifically, the preliminary

15 search and a search including the +42 modification on $\mathrm{K}$ (see searches 1 and 11 ,

16 Supplementary Table 2) were repeated against a reversed sequence database generated

17 from the D. vulgaris database. After applying the same filtering criteria, the number of

18 reversed sequences reported was divided by the number of peptides reported in the

19 original search. Based on this strategy, the false discovery rate was estimated to be 2-3\%.

20 While reverse database searches are useful for determining the number of hits

21 returned by random chance in a given search space, this false positive rate must be

22 equally applied to all sequences returned by the search. Thus, this technique cannot be

23 applied either to confirm or discount results for the subgroup of modified peptides

24 returned by the search. In order to gauge the number of modified sequences typically

25 returned at random by a given search, a different type of decoy search was employed.

26 This series of searches was analogous to searches 11 and 12 (Supplementary Table 2),

27 where iTRAQ modification to each peptide N-terminus and alkylation of cysteines were

28 considered static modifications, while methionine oxidation to sulfoxide and iTRAQ

29 labeling of $\mathrm{Y}$ were allowed as variable modifications. ITRAQ labeling of $\mathrm{K}$ was also

30 allowed as a variable modification along with one of 17 different "false" modification

31 mass shifts, ranging from 1 - 43 Da (see Supplementary Table 7). The masses searched 
1 were chosen to minimize the chances that they may correspond to the addition of known

2 chemical groups (i.e., 5, 13, $20 \mathrm{Da}$ ). Such a search strategy serves as a negative control

3 where only random matches are returned, providing a baseline measurement for the

4 number of hits identified by random chance. This is a similar approach to the PTM

5 frequency matrix proposed by Pevzner and coworkers, applied on a smaller scale ${ }^{40}$. The

6 median number of hits returned in these 17 decoy searches was 8 (Supplementary Table

7 7). This gives further validation that at least the majority of peptides identified with

$8 \mathrm{~K}(+28)$ and $\mathrm{K}(+42)$ modifications are nonrandom and deserve further scrutiny.

Of the predominant PTMs in the four datasets examined in this study, the $+42 \mathrm{Da}$

11 reproducible across the four datasets and passed manual spectrum evaluation. Additional

12 modified proteins were identified having a +42 Da lysine modification in only one of the

13 four datasets. These proteins are listed in Supplementary Tables 3 and 4, but were not

14 investigated further. The six modified peptides of interest mapped to the following $D$.

15 vulgaris proteins: ApsA, ApsB, Sat, DsrC, and RplK (Table 3). It is noteworthy that all of

16 these proteins, with the exception of RplK, are involved in dissimilatory sulfate reduction

17 in D. vulgaris. Based only on the nominal mass shift of $42 \mathrm{Da}$, the modification may

18 either be an acetylation or a trimethylation. Previous mass spectrometry studies of

19 peptides containing acetylated and trimethylated lysine residues have shown that

20 particular MS/MS marker ions can be used to confirm the modified amino acid identity

21 and to distinguish between the two modifications ${ }^{41,42}$. In particular, peptides containing a

22 lysine modified by an acetylation may have an immonium ion at $\mathrm{m} / \mathrm{z} 126$. The

23 unmodified lysine immonium ion originally has a nominal mass of $101 \mathrm{Da}$, but then can

24 undergo an ammonia-elimination reaction yielding an immonium ion at $\mathrm{m} / \mathrm{z} 84$.

25 Trimethylated lysines, on the other hand, produce product ions which may undergo a

26 neutral loss of $59 \mathrm{Da}$, corresponding to the loss of trimethyl-amine, which does not occur

27 for acetylated peptides. Manual examination of the MS/MS data was performed for all

28 six peptides (from Dataset 1) to confirm the location and, where possible, the type of

29 modification on each of these peptides.

30 ApsB was identified with 52\% sequence coverage, and one peptide was identified

31 having a +42 Da modification. The MS/MS data for peptide SADSIMWTVK(+42)FR 
1 (precursor ion $\mathrm{m} / \mathrm{z} 542.90^{3+}$ ) from ApsB are shown in Figure 2a. The $\mathrm{b}$ and $y$-ion series

2 covers the majority of the peptide sequence and definitively localizes the 42 Da mass

3 shift to the TVK residues within the peptide. The fact that the $\mathrm{K}$ was not labeled by the

4 iTRAQ reagent strongly supports that it is the $\mathrm{K}$ and not the $\mathrm{T}$ or $\mathrm{V}$ with the $+42 \mathrm{Da}$

5 modification; the efficiency of iTRAQ labeling on lysine residues was found to be

$699.5 \%$, which would suggest that the $\mathrm{K}$ was already blocked from further modification.

7 Furthermore, the sequence SADSIMWTVKFR contains a missed tryptic cleavage site.

8 Although trypsin cleaves $\mathrm{C}$-terminal to $\mathrm{R}$ and $\mathrm{K}$, cleavage is known to be inhibited at

9 modified $\mathrm{K}$ sites $^{43}$. Indeed, an unmodified form of this peptide was observed as

10 SADSIMWTVK, having an iTRAQ labeled lysine residue. Taken together, the data

11 support a 42 Da modification on K10 within this peptide. The presence of 59 Da neutral

12 losses from the $\mathrm{y}_{6}$ and $\mathrm{y}_{7}$ sequence ions in this peptide indicates that the modification is

13 most likely trimethylation ${ }^{42}$.

14 The DsrC protein was identified with 93\% sequence coverage. Two modified

15 peptides, LK(+42)EVYELFPSGPGK, and ESEGISDISPDHQK(+42)IIDFLQDYYK

16 were observed on this protein. MS/MS data were observed both for the modified

17 LK(+42)EVYELFPSGPGK sequence as well as an oxidized form,

18 LK(+42)EVYELFPS(+16)GPGK; however, this sequence was never observed without

19 the +42 Da mass shift. A spectrum from the oxidized form, having a parent molecular

20 weight of $\mathrm{m} / \mathrm{z} 637.28^{3+}$, is shown in Figure $2 \mathrm{~b}$. The sequence coverage is quite high, and

21 indicates definitively that the oxidation occurs on the $\mathrm{S}$ residue. In this case, the +42

22 modification is localized to the KE residues within the peptide. Again, following the

23 above logic, if the $\mathrm{K}$ were not modified then it should have been ITRAQ labeled, and

24 trypsin should have cleaved the LK residues away from the remaining peptide sequence.

25 Further inspection of the modified MS/MS spectrum reveals the presence of several 59

26 Da neutral losses from the $b$ ion series, indicating that the modification is a trimethylation

27 on the N-terminal end of the peptide. The MS/MS data for

28 ESEGISDISPDHQK(+42)IIDFLQDYYK are shown in Supplementary Figure 2a.

29 Despite the length of this sequence, $y$ and $b$-ion series are present for the entire sequence

30 except the HQKII subsequence, which localizes the +42 Da mass shift to this region.

31 Again, it is important to note the presence of the missed cleavage and lack of iTRAQ

Page 13 of 34 
1 label as indications that the $\mathrm{K}$ is the most likely modified residue. Both

2 ESEGISDISPDHQK and IIDFLQDYYK were independently observed in their

3 unmodified forms, suggesting that the missed cleavage was not a random event.

4 However, in this case, the spectrum does not allow discrimination between acetylation

5 and trimethylation.

Additional MS survey scans for the peptides SADSIMWTVKFR from ApsB and LKEVYELFPSGPGK from DsrC were identified having precursors 14 Da lower in mass

8 than the +42 Da modified precursors. These precursor ions had also been subjected to

9 MS/MS, and Mascot analysis returned the same sequences (SADSIMWTVKFR and

10 LKEVYELFPSGPGK) but modified by +28 instead of $+42 \mathrm{Da}$ at the first $\mathrm{K}$ in each of

11 these peptides. The +28 Da mass shift most likely corresponds to dimethylation, further

12 substantiating that the +42 modification identified for these peptides corresponds to

13 trimethylation.

14 The presence of the sulfate adenyltransferase, Sat, was confirmed by identifying

15 this large protein with $83 \%$ coverage. The peptide VILSGTK(+42)LR, having a

16 precursor ion molecular weight of $\mathrm{m} / \mathrm{z} 586.87^{2+}$, is shown in Figure 2c. Complete

17 sequence coverage by the $\mathrm{b}$ and $\mathrm{y}$-ion series localizes the modification to K7 in the

18 peptide. Of note, this spectrum contains a fairly prominent ion at $\mathrm{m} / \mathrm{z} 126$, which has

19 been previously shown to be a marker for acetylation ${ }^{41,42}$. Additionally, this peptide

20 spectrum does not contain any observed 59 Da neutral loss products.

ApsA was identified with $86 \%$ sequence coverage, and the MS/MS spectrum for

22 the modified peptide DGYGPVGAWFLLFK(+42)AK, having a precursor molecular

23 weight of $\mathrm{m} / \mathrm{z} 700.36^{3+}$, is shown in Supplementary Figure $2 \mathrm{~b}$. The sequence coverage is

24 complete, definitively localizing the +42 Da modification to K14 in the peptide. An

25 immonium ion at $\mathrm{m} / \mathrm{z} 143$ is also present, which corresponds to a +42 Da modified K.

26 Again, the K modification has inhibited cleavage by trypsin. Although the amino acid

27 sequence $\mathrm{N}$-terminal to this peptide is RFK and the C-terminal sequence of this peptide is

28 KAK, neither of the peptides FKDGYGPVGAWFLLFK or

29 FKDGYGPVGAWFLLFKAK is observed, strongly supporting the conclusion that the

30 missed cleavage is not a random event. In this case, the peptide sequence was not 
1 observed with an unmodified counterpart. Unfortunately, the MS/MS spectrum does not

2 provide evidence to discriminate between acetylation and trimethylation in this peptide.

3 One modified lysine residue was identified in RplK. The spectrum for

4 TMEQK (+42)GMITPVVITVYADR is shown in Supplementary Figure 2c. This

5 spectrum has a nearly complete series of fragment ions that localizes the modification to

6 the QK residues of the peptide. Again, the peptide contains a missed cleavage site at the

7 lysine residue, which is not iTRAQ labeled, suggesting that the lysine is the modified

8 amino acid. A second peptide,

9 LQIPAGAANPSPPVGPALGQHGLNIMAFCK(+42)EFNAK, was also returned by the

10 Mascot search algorithm for multiple samples with an expectation value above the 0.05

11 threshold. However, the match did not pass manual inspection due to poor spectrum 12 quality.

13 It should be acknowledged that several known PTMs have the same nominal mass

14 shift as single amino acid substitutions. Single amino acid substitutions become

15 especially prevalent when working with lab strains that have been repeatedly cultivated

16 over many generations, leading to a divergence between the strain being examined and

17 the sequenced strain used to generate the protein database. In the present work, this issue

18 is expected to be minimal because the lab strains utilized in this study were obtained

19 directly from the ATCC stock that provided the original sequence. Culturing protocols

20 were specifically designed to ensure that the biomass used for any experiment was within

21 three subcultures from the original ATCC stock. Furthermore, in many cases diagnostic

22 marker ions were observed in the spectra that support the presence of proposed PTMs, as

23 described above.

Assessment of the +42 Da modification in SRP from alternate workflows. In order to

26 ensure that the observed modifications were not artifacts associated with the iTRAQ

27 workflow in the four datasets analyzed, selected mass spectrometry data from two

28 alternate work flows were also analyzed. As was the case with the previous four datasets,

29 this data was generated as part of separate experiments and was reevaluated as part of this

30 study. These data further confirmed the presence of modified lysine residues in proteins

31 ApsB, ApsA and DsrC. In the first workflow, two D. vulgaris strains were created 
1 incorporating a Strep tag at the terminus of either ApsA or ApsB. A Strep-Tactin column

2 (IBA, Göttingen, Germany) was used to isolate each of these proteins, along with any

3 interacting proteins following standard procedures ${ }^{44}$ (Chhabra et al., in preparation).

4 After reduction, alkylation and tryptic digestion, the resulting peptide mixtures were

5 analyzed by LC/MS/MS and peptide sequences were identified by Mascot using the same

6 criteria outlined in the Methods above. Three peptides were confirmed in these $D$.

7 vulgaris samples: SADSIMWTVK(+42)FR from ApsB with a precursor m/z of $494.9^{3+}$;

8 DGYGPVGAWFLLFK(+42)AK from ApsA with precursors at both $\mathrm{m} / \mathrm{z} 905.9^{2+}$ and

$9604.3^{3+}$; and ESEGISDISPDHQK (+42)IIDFLQDYYK from DsrC having precursors at

10 both $\mathrm{m} / \mathrm{z} 961.4^{3+}$ and $721.3^{4+}$. Note that because iTRAQ labeling was not performed for

11 these samples, the precursor ions for each of these sequences appear at different $\mathrm{m} / \mathrm{z}$

12 values than those reported in Figure 2 and Supplementary Figure 2, even when the same

13 precursor charge state was observed. This is important confirmatory evidence because it

14 precludes the possibility that a particular contaminant at a given $\mathrm{m} / \mathrm{z}$ value was present in

15 one case, and caused a false positive match to one of these modified sequences. In a

16 second set of experiments, D. vulgaris proteins were resolved by two-dimensional

17 electrophoresis. The spots were cut out, digested in-gel with trypsin, and the proteins

18 were identified using a peptide mass fingerprint approach ${ }^{3}$. In particular, the DsrC

19 protein was observed to contain the peptide LK(+42)EVYELFPSGPGK as well as the

20 oxidized form of this peptide. Tandem mass spectra were acquired on this peptide and

21 found to be consistent with the conclusions presented above, namely: the spectrum

22 localized the 42 Da mass shift to the LK peptide N-terminal subsequence, the observation

23 of several 59 Da neutral loss product ions indicates that the modification is most likely

24 trimethylation, and the oxidized peptide version has the +16 Da modification within the

25 PSG subsequence.

Assessment of the +42 Da modifications in D. desulfuricans G20, another SRB. The majority of the +42 Da PTM maps to sulfate reducing proteins in $D$. vulgaris, where an

29 earlier analysis of the genes encoded by sulfate reducing bacteria suggested that these

30 were among the signature genes ${ }^{3}$. To find out if this modification was more generally

31 applicable to other SRB, the proteome of Desulfovibrio desulfuricans G20 was examined 
1 to assess if the +42 Da modification could also be detected. G20 biomass was grown in

2 LS4D, and the cellular lysis, denaturation, and reduction were performed using the same

3 protocols used for $D$. vulgaris, with the exception that the cysteine residues were blocked

4 with iodoacetamide for $30 \mathrm{~min}$. Examination of the sulfate reducing homologs identified

5 the +42 Da modification on two analogous peptides in G20, namely the

6 LK(+42)QVYELFPSGPGK peptide from DsrC and the DGYGPVGAWFLLFK(+42)AK

7 peptide from ApsA. Although the spectra produced in this study were unable to provide

8 sufficient evidence to distinguish between trimethylation or acetylation, the presence of

9 these modifications was established in D. desulfuricans G20, even where the peptide

10 sequences differ slightly from those observed in D. vulgaris. Thus, the presence of these

11 modifications in other homologous sulfate reducing pathways was confirmed.

13 Additional PTMs. Determining which modified peptides were observed in multiple

14 datasets allowed targeted selection of seven peptides having a $K(+42)$ modification of

15 which six passed manual inspection/confirmation. A similar analysis was performed for

16 the other modified peptides of interest, revealing 11 peptides containing $\mathrm{K}(+28), 23$

17 peptides having $\mathrm{P}(+16)$, and 22 peptides with $\mathrm{D} / \mathrm{E}(+14)$ mass shifts. The sequence data

18 are summarized in Supplementary Table 8, where the peptides are grouped by

19 modification type and sorted by sequence length. However, the median size of peptides

20 observed with the $\mathrm{K}+42$ modification was 16 , while it was much smaller for the others.

21 This may be because these other modifications do not inhibit trypsin activity, leading to

22 shorter sequence lengths overall. Interestingly, in no other case were a significant

23 number of modified proteins found to belong to members of the same pathway. While it

24 may be that these are legitimate modifications containing interesting biological stories,

25 we elected not to pursue them as part of this study.

\section{DISCUSSION}

28 Regulation at the protein level is being recognized as an integral component of

29 cell wide functions and post translational modifications form an important part of these

30 regulatory processes. However, very little is yet known about any PTMs in D. vulgaris.

31 Thirty-five modifications of interest were identified from literature and databases and 
1 four large proteomics datasets were screened for them. While several PTMs were

2 identified using this data-mining technique, $a+42$ Da modification on lysine residues was

3 the only modification that appeared consistently across multiple datasets. This $+42 \mathrm{Da}$

4 mass shift was reproducibly identified on 6 distinct peptides, where each modification

5 was represented in at least two separate datasets. Decoy searches of lysine residues

6 further confirmed the specificity of these results. Interestingly, the majority of these

7 modifications mapped to proteins that were linked functionally, being members of the

8 sulfate reduction pathway (SRP). The candidates involved in sulfate reduction appear to

9 be highly abundant evidenced by both high absolute mRNA levels ${ }^{45}$ and many peptide

10 observations in proteomics datasets. However, the presence of this modification on the

11 SRP proteins cannot be attributed to high abundance, as other pathways that appear to be

12 similarly abundant did not display this modification. In fact, the only exception among

13 the 1100 proteins identified was for RplK, the ribosomal subunit L11, which had one +42

14 modification site. Two factors supported the physiological relevance of this modification

15 in the sulfate reduction pathway. This modification was observed in multiple datasets

16 from orthologous work flows, and homologs of the SRP protein in the closely related $D$.

17 desulfuricans also contained modified lysine residues at the same loci.

18 All organisms contain assimilatory sulfate reduction complexes, which enable the

19 incorporation of sulfur into metabolites. However, in SRB where sulfate also serves as

20 an electron acceptor and is postulated to be the primary source of energy, the

21 dissimilatory $\mathrm{SRP}^{46}$ is encoded by signature genes conserved across all $\mathrm{SRB}^{3}$. The

22 annotated SRP in D. vulgaris is depicted in Figure 3. The first step, required in all sulfate

23 utilization pathways, assimilatory or dissimilatory, is the conversion of sulfate into the

24 activated intermediate adenylyl sulfate (APS), and is effected via the sulfate

25 adenylyltransferase (Sat), also called ATP sulfurylase ${ }^{47}$. Once formed in the

26 dissimilatory pathway, APS is reduced to sulfite via the APS reductase complex,

27 comprised of ApsA and ApsB. For the final conversion of bisulfite to sulfide, the

28 bisulfite reductase, also referred to as dissimilatory sulfite reductase (Dsr) or

29 desulfoviridin $^{48}$, is the primary protein complex involved ${ }^{49}$. The most interesting

30 discovery in this study is that each of the enzymatic steps in the sulfate reduction

31 pathway delineated above contains at least one lysine residue with the +42 modification. 
1 In almost all cases, the modified lysine loci as well as the neighboring sequence are

2 highly conserved. Exceptions to this include the K78 of DsrC and the K382 of Sat;

3 however, in these instances the locus harbors a positively charged residue.

4 It is difficult to assess the impact of a PTM on the function of a protein with no

5 information about its structure. The only protein in this pathway that has been crystallized

6 in any organism is $\mathrm{DsrC}^{50-52}$. To obtain a better understanding of the implications of the

7 protein modifications, crystal structures from the homologous DsrC proteins were

8 investigated. The Archeoglobus fulgidus $\mathrm{DsrC}$ has the highest homology to the $D$.

9 vulgaris $\mathrm{DsrC}$ sequence and was used as the scaffold for modeling (Figure 4B). As the

10 model shows, the modified lysines appear on two distinct faces of the three dimensional

11 structure and are both present on helices. A helical wheel rendering of these predicted

12 helices also show them to be amphiphilic with the modified lysine on the charged face

13 (Figure 4C). Previous studies of protein methylation revealed that trimethylation can

14 stabilize $\alpha$-helix structures ${ }^{53}$. It is therefore interesting to speculate that the purpose of

15 these modified lysines may be to stabilize the charged face of the helix. The DsrC

16 enzyme in $D$. vulgaris forms part of the DsrABC complex ${ }^{54}$, although this may not be the

17 case in the A. fulgidus ${ }^{50}$. DsrC is also predicted to interact with the DsrMKJOP

18 complex ${ }^{54-56}$. As both the PTMs point outward rather than inward, a modification at

19 either of these positions may impact protein-protein interactions ${ }^{57}$. The regions important

20 for these protein-protein interactions need to be elucidated to validate this hypothesis.

21 In this study, several of the +42 Da modifications observed appear to be

22 trimethylations primarily associated with sulfate reduction in D. vulgaris. Many putative

23 methyl- and acetyltransferases have been annotated in the D. vulgaris genome, providing

24 potential pathways capable of generating these modifications. Although iTRAQ labeling

25 allowed determination of total protein expression in stressed relative to control

26 conditions $^{11,35}$, the individual peptide data was not sufficient to determine whether these

27 modifications occurred as a function of the stress treatments. Biochemical evidence needs

28 to be found to establish the presence and physiological relevance of these PTMs

29 unequivocally. For non-model organisms such as D. vulgaris, recent advances in genetic

30 tools provide the means for such follow up work ${ }^{58,59}$. The discovery of this modification 
1 in multiple proteins of this critical pathway and in another sulfate reducing bacteria

2 makes it an ideal candidate for such experimental validation.

4 ACKNOWLEDGEMENTS

5 We thank Dr. Subodh Nimkar (Applied Biosystems), Dr. Swapnil Chhabra

6 (Lawrence Berkeley National Laboratory), and Dr. Christopher Petzold (QB3) for

7 assistance with mass spectrometric data acquisition and insightful comments. We are

8 grateful to Melinda Clark (Montana University) for D. vulgaris biofilm sample

9 preparation and Dominique Joyner (Lawrence Berkeley National Laboratory) for

10 providing the $D$. desulfuricans culture. We appreciate Dr. Judy Wall for engaging in

11 helpful discussions and critically reviewing the manuscript. This work is part of the

12 Virtual Institute for Microbial Stress and Survival (http://vimss.lbl.gov) supported by the

13 U.S. Department of Energy, Office of Science, Office of Biological and Environmental

14 Research, Genomics:GTL Program through contract DE-AC02-05CH11231 between the

15 Lawrence Berkeley National Laboratory and the US Department of Energy.

16

17 SUPPORTING INFORMATION AVAILABLE

18 Supplementary Figures 1-2 and Supplementary Tables 1-8 are available free of

19 charge via the Internet at http://pubs.acs.org. 


\section{REFERENCES}

(1) Fang, R.; Elias, D. A.; Monroe, M. E.; Shen, Y.; McIntosh, M.; Wang, P.; Goddard, C. D.; Callister, S. J.; Moore, R. J.; Gorby, Y. A.; Adkins, J. N.; Fredrickson, J. K.; Lipton, M. S.; Smith, R. D., Differential label-free quantitative proteomic analysis of Shewanella oneidensis cultured under aerobic and suboxic conditions by accurate mass and time tag approach. Mol Cell Proteomics 2006, 5(4), 714-25.

(2) Lipton, M. S.; Romine, M. F.; Monroe, M. E.; Elias, D. A.; Pasa-Tolic, L.; Anderson, G. A.; Anderson, D. J.; Fredrickson, J.; Hixson, K. K.; Masselon, C.; Mottaz, H.; Tolic, N.; Smith, R. D., AMT tag approach to proteomic characterization of Deinococcus radiodurans and Shewanella oneidensis. Methods Biochem Anal 2006, 49, 113-34.

(3) Chhabra, S. R.; He, Q.; Huang, K. H.; Gaucher, S. P.; Alm, E. J.; He, Z.; Hadi, M. Z.; Hazen, T. C.; Wall, J. D.; Zhou, J.; Arkin, A. P.; Singh, A. K., Global Analysis of Heat Shock Response in Desulfovibrio vulgaris Hildenborough. J Bacteriol 2006, 188(5), 1817-28.

(4) Ram, R. J.; Verberkmoes, N. C.; Thelen, M. P.; Tyson, G. W.; Baker, B. J.; Blake, R. C., 2nd; Shah, M.; Hettich, R. L.; Banfield, J. F., Community proteomics of a natural microbial biofilm. Science 2005, 308(5730), 1915-20.

(5) Rosen, R.; Ron, E. Z., Proteome analysis in the study of the bacterial heat-shock response. Mass Spectrom Rev 2002, 21(4), 244-65.

(6) Luo, Q.; Tang, K.; Yang, F.; Elias, A.; Shen, Y.; Moore, R. J.; Zhao, R.; Hixson, K. K.; Rossie, S. S.; Smith, R. D., More sensitive and quantitative proteomic measurements using very low flow rate porous silica monolithic LC columns with electrospray ionization-mass spectrometry. J Proteome Res 2006, 5(5), 1091-7.

(7) Wolters, D. A.; Washburn, M. P.; Yates, J. R., 3rd, An automated multidimensional protein identification technology for shotgun proteomics. Anal Chem 2001, 73(23), 5683-90.

(8) MacCoss, M. J.; McDonald, W. H.; Saraf, A.; Sadygov, R.; Clark, J. M.; Tasto, J. J.; Gould, K. L.; Wolters, D.; Washburn, M.; Weiss, A.; Clark, J. I.; Yates, J. R., Shotgun identification of protein modifications from protein complexes and lens tissue. Proceedings of the National Academy of Sciences of the United States of America 2002, 99(12), 7900-7905.

(9) Mukhopadhyay, A.; He, Z.; Alm, E. J.; Arkin, A. P.; Baidoo, E. E.; Borglin, S. C.; Chen, W.; Hazen, T. C.; He, Q.; Holman, H.-Y.; Huang, K.; Huang, R.; Joyner, D. C.; Katz, N.; Keller, M.; Oeller, P.; Redding, A.; Sun, J.; Wall, J.; Wei, J.; Yang, Z.; Yen, H.-C.; Zhou, J.; Keasling, J. D., Salt stress in Desulfovibrio vulgaris Hildenborough: an integrated genomics approach. J. Bacteriol. 2006, 188(11), 4068-4078.

(10) Mukhopadhyay, A.; Redding, A. M.; Joachimiak, M. P.; Arkin, A. P.; Borglin, S. E.; Dehal, P. S.; Chakraborty, R.; Geller, J. T.; Hazen, T. C.; He, Q.; Joyner, D. C.; Martin, V. J. J.; Wall, J. D.; Yang, Z. K.; Zhou, J.; Keasling, J. D., Cell wide responses to low oxygen exposure in Desulfovibrio vulgaris Hildenborough. $J$. Bacteriol. 2007, JB.00368-07. 
(11) Redding, A. M.; Mukhopadhyay, A.; Joyner, D. C.; Hazen, T. C.; Keasling, J. D., Study of nitrate stress in Desulfovibrio vulgaris Hildenborough using iTRAQ proteomics. Brief Funct Genomic Proteomic 2006, 5(2), 133-143.

(12) Thompson, M. R.; Thompson, D. K.; Hettich, R. L., Systematic Assessment of the Benefits and Caveats in Mining Microbial Post-Translational Modifications from Shotgun Proteomic Data: The Response of Shewanella oneidensis to Chromate Exposure. Journal of Proteome Research 2008, Web Release Jan. 2.

(13) Vasilescu, J.; Smith, J. C.; Zweitzig, D. R.; Denis, N. J.; Haines, D. S.; Figeys, D., Systematic determination of ion score cutoffs based on calculated false positive rates: application for identifying ubiquitinated proteins by tandem mass spectrometry. Journal of Mass Spectrometry 2007, 9999(9999), n/a.

(14) Gupta, N.; Tanner, S.; Jaitly, N.; Adkins, J. N.; Lipton, M.; Edwards, R.; Romine, M.; Osterman, A.; Bafna, V.; Smith, R. D.; Pevzner, P. A., Whole proteome analysis of post-translational modifications: Applications of mass-spectrometry for proteogenomic annotation. Genome Research 2007, 17(9), 1362-1377.

(15) Szurmant, L.; Ordal, G. W., Diversity in chemotaxis mechanisms among the bacteria and archaea. Microbiology and Molecular Biology Reviews 2004, 68(2), 301-319.

(16) Young, C. C.; Bernlohr, R. W., Elongation Factor-Tu Is Methylated in Response to Nutrient Deprivation in Escherichia-coli. Journal of Bacteriology 1991, 173(10), 3096-3100.

(17) Polevoda, B.; Sherman, F., Methylation of proteins involved in translation. Molecular Microbiology 2007, 65(3), 590-606.

(18) Gardner, J. G.; Grundy, F. J.; Henkin, T. A.; Escalante-Semerena, J. C., Control of acetyl-coenzyme A synthetase (AcsA) activity by acetylation/deacetylation without $\mathrm{NAD}(+)$ involvement in Bacillus subtilis. Journal of Bacteriology 2006, 188(15), 5460-5468.

(19) Barak, R.; Yan, J.; Shainskaya, A.; Eisenbach, M., The chemotaxis response regulator CheY can catalyze its own acetylation. Journal of Molecular Biology 2006, 359(2), 251-265.

(20) Kim, S. C.; Sprung, R.; Chen, Y.; Xu, Y. D.; Ball, H.; Pei, J. M.; Cheng, T. L.; Kho, Y.; Xiao, H.; Xiao, L.; Grishin, N. V.; White, M.; Yang, X. J.; Zhao, Y. M., Substrate and functional diversity of lysine acetylation revealed by a proteomics survey. Molecular Cell 2006, 23(4), 607-618.

(21) Zhang, X. H.; Yuan, Z. G.; Zhang, Y. T.; Yong, S.; Salas-Burgos, A.; Koomen, J.; Olashaw, N.; Parsons, J. T.; Yang, X. J.; Dent, S. R.; Yao, T. P.; Lane, W. S.; Seto, E., HDAC6 modulates cell motility by altering the acetylation level of cortactin. Molecular Cell 2007, 27(2), 197-213.

(22) Gonzales, T.; RobertBaudouy, J., Bacterial aminopeptidases: Properties and functions. Fems Microbiology Reviews 1996, 18(4), 319-344.

(23) Lee, J. W.; Helmann, J. D., The PerR transcription factor senses $\mathrm{H}_{2} \mathrm{O}_{2}$ by metalcatalysed histidine oxidation. Nature 2006, 440(7082), 363-7.

(24) Stock, A. M.; Robinson, V. L.; Goudreau, P. N., Two-component signal transduction. Annual Review of Biochemistry 2000, 69, 183-215.

(25) Freestone, P.; Nystrom, T.; Trinei, M.; Norris, V., The universal stress protein, UspA, of Escherichia coli is phosphorylated in response to stasis. $J$ Mol Biol 1997, 274(3), 318-24.

Page 22 of 34 
(26) Upreti, R. K.; Kumar, M.; Shankar, V., Bacterial glycoproteins: Functions, biosynthesis and applications. Proteomics 2003, 3(4), 363-379.

(27) Hayashi, S.; Wu, H. C., Lipoproteins in Bacteria. Journal of Bioenergetics and Biomembranes 1990, 22(3), 451-471.

(28) Eichler, J.; Adams, M. W. W., Posttranslational protein modification in Archaea. Microbiology and Molecular Biology Reviews 2005, 69(3), 393-425.

(29) Villar-Garea, A.; Imhof, A., The analysis of histone modifications. Biochimica Et Biophysica Acta-Proteins and Proteomics 2006, 1764(12), 1932-1939.

(30) Kimura, A.; Matsubara, K.; Horikoshi, M., A decade of histone acetylation: Marking eukaryotic chromosomes with specific codes. Journal of Biochemistry 2005, 138(6), 647-662.

(31) Latham, J. A.; Dent, S. Y. R., Cross-regulation of histone modifications. Nature Structural \& Molecular Biology 2007, 14(11), 1017-1024.

(32) Morgunkova, A.; Barlev, N. A., Lysine methylation goes global. Cell Cycle 2006, 5(12), 1308-1312.

(33) Yang, X. J.; Gregoire, S., Metabolism, cytoskeleton and cellular signalling in the grip of protein N-epsilon- and O-acetylation. Embo Reports 2007, 8(6), 556-562.

(34) VerBerkmoes, N. C.; Bundy, J. L.; Hauser, L.; Asano, K. G.; Razumovskaya, J.; Larimer, F.; Hettich, R. L.; Stephenson, J. L., Integrating "top-down" and "bottom-up" mass spectrometric approaches for proteomic analysis of Shewanella oneidensis. Journal of Proteome Research 2002, 1(3), 239-252.

(35) Mukhopadhyay, A.; Redding, A. M.; Joachimiak, M. P.; Arkin, A. P.; Borglin, S. E.; Dehal, P. S.; Chakraborty, R.; Geller, J. T.; Hazen, T. C.; He, Q.; Joyner, D. C.; Martin, V. J. J.; Wall, J. D.; Yang, Z. K.; Zhou, J.; Keasling, J. D., Cell wide responses to low oxygen exposure in Desulfovibrio vulgaris Hildenborough. $J$. Bacteriol. 2007, 5996-6010.

(36) Alm, E. J.; Huang, K. H.; Price, M. N.; Koche, R. P.; Keller, K.; Dubchak, I. L.; Arkin, A. P., The MicrobesOnline Web site for comparative genomics. Genome Res 2005, 15(7), 1015-22.

(37) Ross, P. L.; Huang, Y. N.; Marchese, J. N.; Williamson, B.; Parker, K.; Hattan, S.; Khainovski, N.; Pillai, S.; Dey, S.; Daniels, S.; Purkayastha, S.; Juhasz, P.; Martin, S.; Bartlet-Jones, M.; He, F.; Jacobson, A.; Pappin, D. J., Multiplexed protein quantitation in Saccharomyces cerevisiae using amine-reactive isobaric tagging reagents. Mol Cell Proteomics 2004, 3(12), 1154-69.

(38) Robinson, A. B.; Scotchle.Jw; McKerrow, J. H., Rates of Nonenzymatic Deamidation of Glutaminyl and Asparaginyl Residues in Pentapeptides. Journal of the American Chemical Society 1973, 95(24), 8156-8160.

(39) Lagerwerf, F. M.; vandeWeert, M.; Heerma, W.; Haverkamp, J., Identification of oxidized methionine in peptides. Rapid Communications in Mass Spectrometry 1996, 10(15), 1905-1910.

(40) Tsur, D.; Tanner, S.; Zandi, E.; Bafna, V.; Pevzner, P. A., Identification of posttranslational modifications by blind search of mass spectra. Nature Biotechnology 2005, 23(12), 1562-1567.

(41) Kim, J. Y.; Kim, K. W.; Kwon, H. J.; Lee, D. W.; Yoo, J. S., Probing lysine acetylation with a modification-specific marker ion using high-performance liquid 
chromatography/electrospray-mass spectrometry with collision-induced dissociation. Analytical Chemistry 2002, 74(21), 5443-5449.

(42) Zhang, K. L.; Yau, P. M.; Chandrasekhar, B.; New, R.; Kondrat, R.; Imai, B. S.; Bradbury, M. E., Differentiation between peptides containing acetylated or trimethylated lysines by mass spectrometry: An application for determining lysine 9 acetylation and methylation of histone H3. Proteomics 2004, 4(1), 1-10.

(43) Rice, R. H.; Means, G. E.; Brown, W. D., Stabilization of Bovine Trypsin by Reductive Methylation. Biochimica Et Biophysica Acta 1977, 492(2), 316-321.

(44) Schmidt, T. G.; Skerra, A., The Strep-tag system for one-step purification and highaffinity detection or capturing of proteins. Nature Protocols 2007, 2, 1528-1535.

(45) Arkin, A. P. Absolute Expression Estimates. http://genomics.lbl.gov/VIMSS/expression.html November, 2007

(46) Peck, H. D.; Legall, J.; Vanbeeumen, J., Biochemistry of Dissimilatory Sulfate Reduction. Philosophical Transactions of the Royal Society of London Series BBiological Sciences 1982, 298(1093), 443-466.

(47) Akagi, J. M., Respiratory Sulfate Reduction. In Sulfate-Reducing Bacteria, Barton, L. L., ed., Plenum Press: New York, 1995; Biotechnology Handbooks Vol. 8, p 89-108.

(48) Lee, J. P.; Legall, J.; Peck, H. D., Isolation of Assimilatory-type and Dissimilatorytype Sulfite Reductases from Desulfovibrio-vulgaris. Journal of Bacteriology 1973, 115(2), 529-542.

(49) Hansen, T. A., Metabolism of Sulfate-Reducing Prokaryotes. Antonie Van Leeuwenhoek International Journal of General and Molecular Microbiology 1994, 66(1-3), 165-185.

(50) Mander, G. J.; Weiss, M. S.; Hedderich, R.; Kahnt, J.; Ermler, U.; Warkentin, E., Xray structure of the gamma-subunit of a dissimilatory sulfite reductase: fixed and flexible C-terminal arms. FEBS Lett 2005, 579(21), 4600-4.

(51) Cort, J. R.; Mariappan, S. V.; Kim, C. Y.; Park, M. S.; Peat, T. S.; Waldo, G. S.; Terwilliger, T. C.; Kennedy, M. A., Solution structure of Pyrobaculum aerophilum DsrC, an archaeal homologue of the gamma subunit of dissimilatory sulfite reductase. Eur J Biochem 2001, 268(22), 5842-50.

(52) Weiss, M. S.; Mander, G.; Hedderich, R.; Diederichs, K.; Ermler, U.; Warkentin, E., Determination of a novel structure by a combination of long-wavelength sulfur phasing and radiation-damage-induced phasing. Acta Crystallographica Section D 2004, 60(4), 686-695.

(53) Bello, J., Helix Formation in Poly (N-Epsilon,N-Epsilon,N-Epsilon-Trimethyl-LLysine) and Poly(L-Lysine) - Dependence on Concentration and MolecularWeight. Biopolymers 1992, 32(2), 185-188.

(54) Pierik, A. J.; Duyvis, M. G.; Vanhelvoort, J.; Wolbert, B. G.; Hagen, W. R., The 3rd Subunit of Desulfoviridin-type Dissimilatory Sulfite Reductases. European Journal of Biochemistry 1992, 205(1), 111-115.

(55) Pires, R. H.; Venceslau, S. S.; Morais, F.; Teixeira, M.; Xavier, A. V.; Pereira, I. A. C., Characterization of the Desulfovibrio desulfuricans ATCC 27774 DsrMKJOP complex - A membrane-bound redox complex involved in the sulfate respiratory pathway. Biochemistry 2006, 45(1), 249-262. 
(56) Sander, J.; Engels-Schwarzlose, S.; Dahl, C., Importance of the DsrMKJOP complex for sulfur oxidation in Allochromatium vinosum and phylogenetic analysis of related complexes in other prokaryotes. Archives of Microbiology 2006, 186(5), 357-366.

(57) Pang, C. N. I.; Hayen, A.; Wilkins, M. R., Surface accessibility of protein posttranslational modifications. Journal of Proteome Research 2007, 6(5), 1833-1845.

(58) Wall, J. D.; Hemme, C. L.; Rapp-Giles, B.; Ringbauer, J. A., Jr.; Casalot, L.; Giblin, T., Genes and genetic manipulations of Desulfovibrio. In Biochemistry and physiology of anaerobic bacteria, Ljungdahl, L. G.; Adams, M. W. W.; Barton, L. L.; Ferry, J. G.; Johnson, M. K., ed., Springer: New York, 2003; Vol. p 85-98.

(59) Bender, K. S.; Yen, H.-C.; Wall, J. D., Analysing the metabolic capabilities of Desulfovibrio species through genetic manipulations. In Biotechnology \& genetic engineering reviews, Harding, S. E., ed., Nottingham University Press: Lavoisier, France, 2006; Vol. 23, p 157-174. 


\section{FIGURE CAPTIONS}

Figure 1. Flowchart for identifying protein post-translational modifications. Four LC/MS/MS datasets (approximately 86,040 spectra) from Desulfovibrio vulgaris Hildenborough were peakpicked using MatrixScience Distiller and subjected to a preliminary Mascot search. Dataset 1 was identified as the most comprehensive file, and was used to screen all other modifications. The efficiencies of iTRAQ labeling and cysteine blockage were evaluated to ensure that the most appropriate search space was utilized. MS/MS peak lists were submitted to Mascot in 23 separate searches using different static and variable modifications. In vivo modifications with the greatest number of peptides were identified as "target modifications": $\mathrm{P}(+18), \mathrm{K}(+28), \mathrm{D} / \mathrm{E}(+14)$, $\mathrm{K}(+42)$. Peak lists from the other three datasets were individually submitted to separate Mascot searches with the target modifications specified. Raw spectra were extracted from Dataset 1 for modified peptides identified in at least two datasets and sequence assignments were manually validated.

Figure 2. QStar ESI-MS/MS data (A) Peptide (iTRAQ)SADSIMWTVK(+42)FR from ApsB. The peptide fragmentation pattern localizes the modification to the TVK residues within the peptide. The fact that the K10 of this peptide is not iTRAQ labeled $(0.5 \%$ occurrence) and that this represents a missed trypsin cleavage site both suggest that K10 has been modified. Further, the presence of $y_{6}-59$ and $y_{7}-59$ ions is consistent with this modification being a trimethylation event occurring on the $\mathrm{C}$-terminal end of the peptide.

(B) Peptide (iTRAQ)LK(+42)EVYELFPS(+16)GPGK(iTRAQ) from DsrC. This fragmentation series localizes the modification to the KE amino acids within the peptide. This peptide likewise contains a missed tryptic cleavage and the K2 remains unlabeled by iTRAQ reagents, suggesting that the lysine is the labeled residue. In this case, the b-ion series contains several -59 losses $\left(b_{6}, b_{7}, b_{8}\right)$, which is indicative that the modification is a trimethylation on the N-terminal end of the peptide. This peptide also has an oxididation on the $\mathrm{S} 10$ residue, which is clearly identified from the ion series. The unoxidized form of this peptide was also identified, although this peptide was never observed without the +42 modification. (C) Peptide (iTRAQ)VILSGTK(+42)LR from Sat. In this spectrum, the fragmentation series is complete and clearly localizes the modification to the $\mathrm{K} 7$ 
residue. Unlike the previous two examples, there is a strong immonium ion at 126.1, which has been shown to be a marker for acetylation. Consistent with this, there are no $59 \mathrm{Da}$ losses present in the spectrum.

Figure 3. A diagram of the known sulfate reduction pathway (SRP) in D. vulgaris. The chemical structures of intermediates of the SRP are shown. Enzymes completing the intermediate steps are given. The percent coverage for each protein is shown, along with the corresponding modified peptides that were identified. As can be seen, every major member of this pathway has at least one peptide containing a modified lysine residue.

Figure 4. DsrC Modeling (A) A ClustalW alignment of DsrC proteins from multiple organisms is shown. D. vulgaris and D. desulfuricans G20 are shown, and the high homology between them can be noted. The additional proteins in the alignment were selected based on the fact that crystal structures have been described for these DsrC proteins. (B) Model of DvH DrsC using the Archeoglobus fulgidus DsrC as template, as it has the highest homology of the crystallized DsrC proteins. As can be observed, both of the modified lysine residues point away from the DsrC protein itself. (C) A view of the residues involved in the helices containing the modified residues. Both of these helices are amphipathic. 
Figure 1.

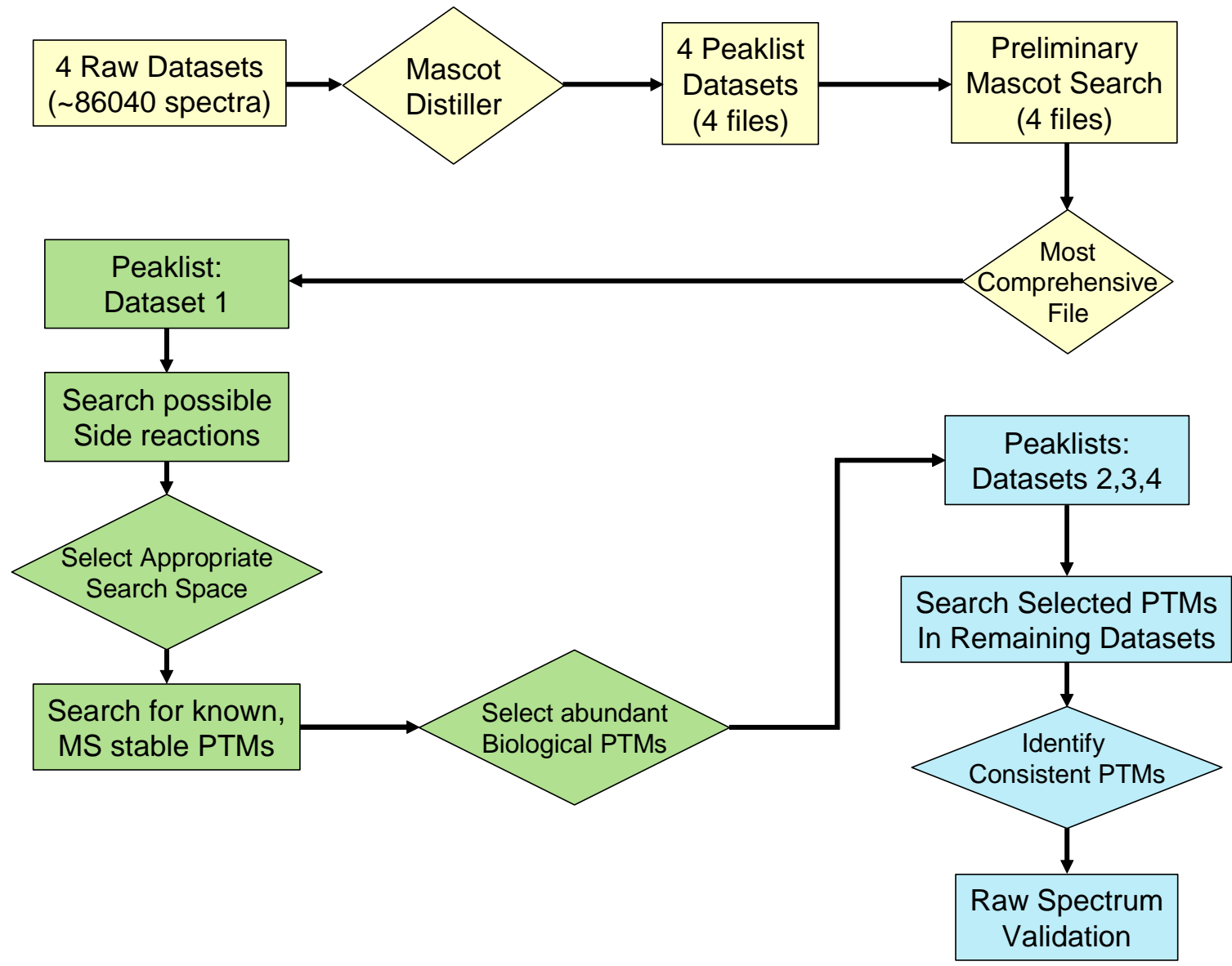

Page 28 of 34 
Figure 2

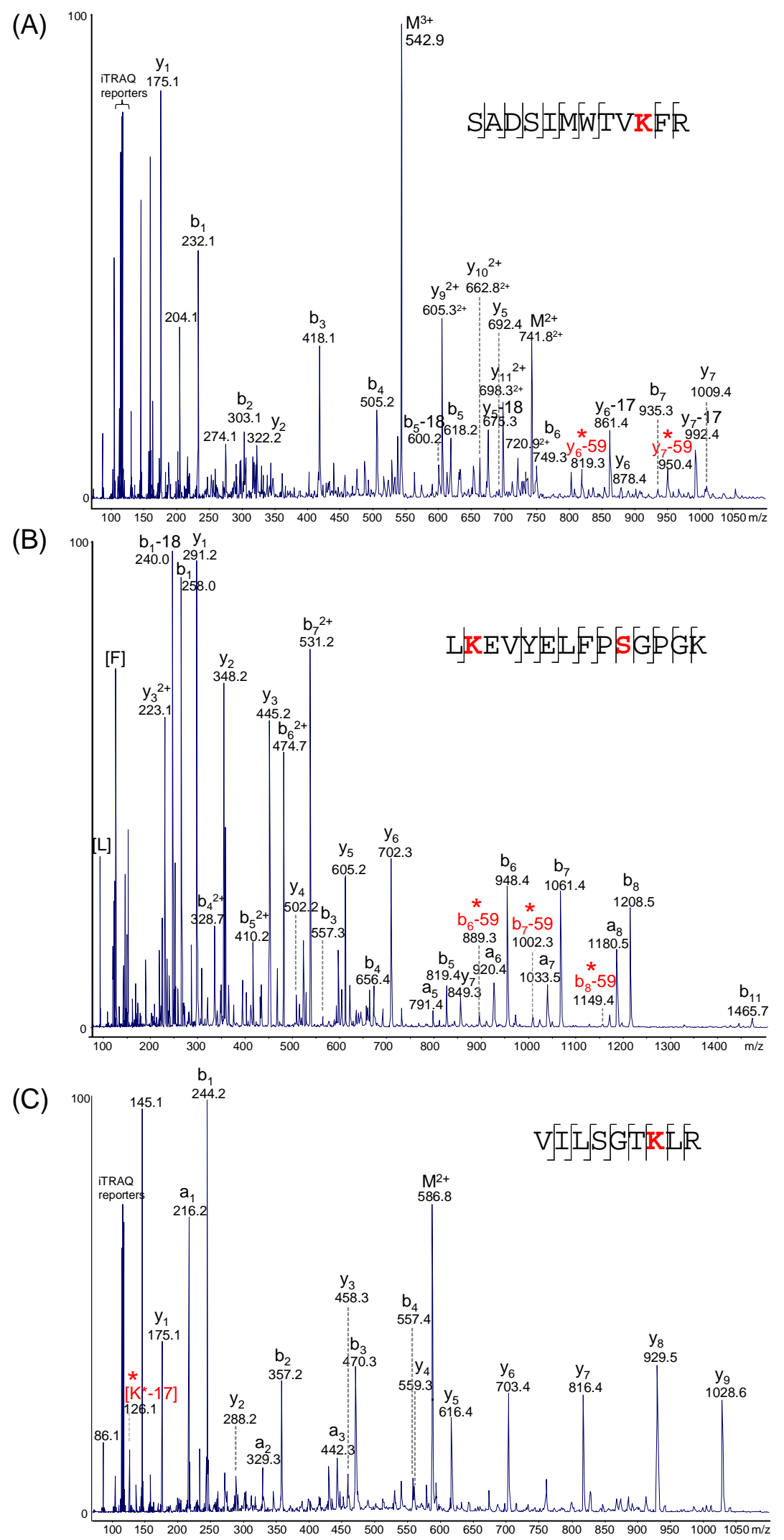


Figure 3.

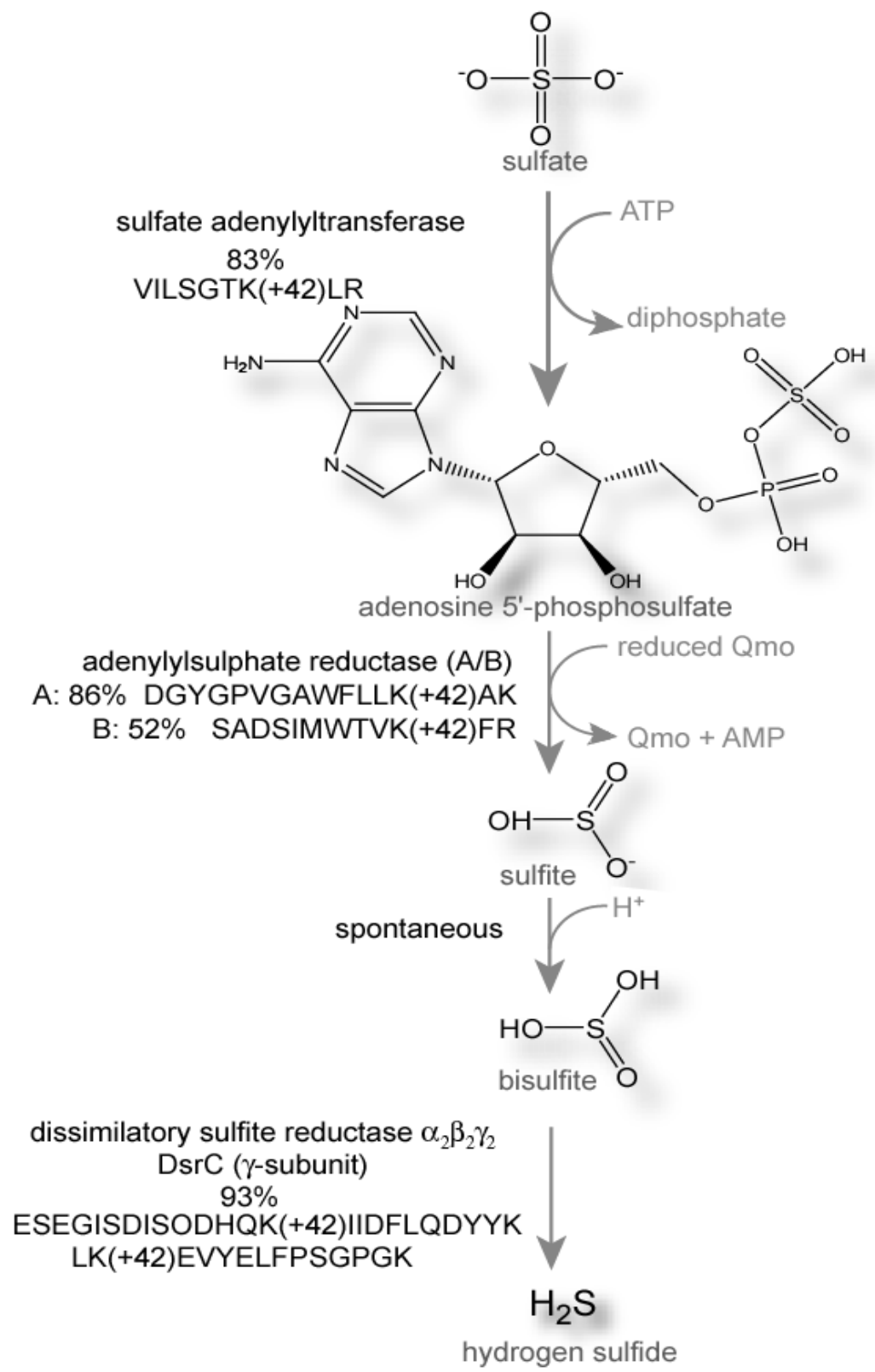

Page 30 of 34 


\section{Figure 4.}

(A)

D. vulgaris

D. desulfuricansG20

A. fulgidus

P. aerophilum

A. vinosum

D. vulgaris

D. desulfuricansG20

A. fulgidus

P. aerophilum

A. vinosum

D. vulgaris

D. desulfuricansG20

A. fulgidus

P. aerophilum

A. vinosum
-------------------MAE-----VTYKGKSFEVDEDGFIRRFDDWCPEWVEYVK- 34 --------------------MAE-----VSFQGKTFEVDEDGF LLRFDEWCPEWVEYVK- 34 ------------------MP-----ELEVKGKKLRLDEDGF LQDWEEWDEEVAEALAK 35 --------------------MPVKCP GEYQVDGKKVI LDEDCFMQNPEDWDEKVAEWLAR 40 MGSSHHHHHHSSGLVPRGSHMADT----IEVDGKQFAVDEEGYLSNLNDWVPG-VADVM- 54

ESEGISD---ISPDHQKI IDFLQDYYKKNGIAPMVRILSKNTGFKL-------KEVYELF 84 ESEGIAE---ITEDHQKI IDF LQDYYRKNGIAPMVRI LSKNTGFKL-------KQVYELF 84 DTRF SPQP IELTEEHWKI IRYLRDYF IKYGVAP PVRMLVKHCKKEV-RPDCNLQYIYKLF 94 ELEGIOK---MTEEHWKLVKYLREYWETFGTCPP IKMVTKETG-------F SLEKIYOLF 90 AKQDNLE---LTEEHWD I INF LREYYEEYQIAPAVRVLTKAVGKKLGKEKGNSKYLYSLF 11

PSGPGKGACKMAGLPKPTGCV 105

PSGPGKGACKMAGLPKPTGCV 105 POGPAKDACRIAGLPKPTGCV 115

PSGPAHGACKVAGAPKPTGCV 111

PYGPAKQACRFAGLPKPTGCV 132

(B)

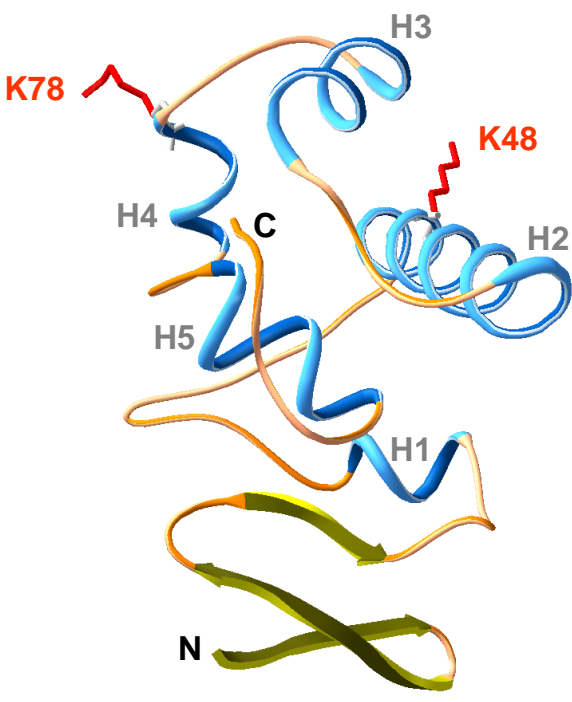

(C)

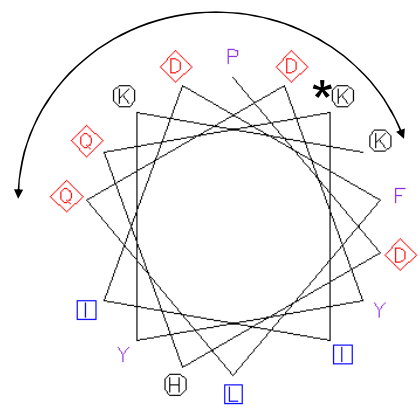

H2: PDHQK ${ }^{*}$ IIDFLQDYYKK

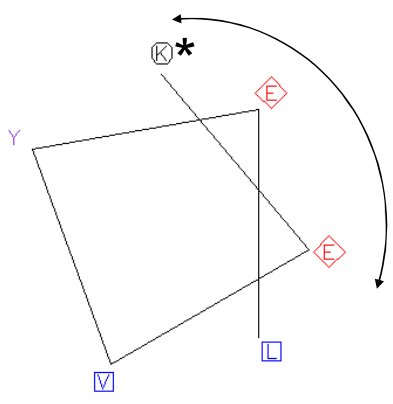

H4: $K^{*}$ LKEVYEL

Page 31 of 34 
Table 1. Summary of amino acid modifications found in Dataset 1 searches. Each unique peptide sequence was counted only once, where the same sequence modified in 2 different ways would count as 2 sequences. Supplementary table 2 lists the parameters used in each search specified.

\begin{tabular}{|c|c|c|c|c|}
\hline \begin{tabular}{|l|} 
Putative \\
Modification
\end{tabular} & $\begin{array}{l}\text { Amino } \\
\text { Acid }\end{array}$ & $\begin{array}{c}\text { Delta } \\
\text { Mass (Da) }\end{array}$ & $\begin{array}{c}\text { \# Unique } \\
\text { Sequences }\end{array}$ & $\begin{array}{c}\text { Results from } \\
\text { Search \# }\end{array}$ \\
\hline \multirow{5}{*}{ iTRAQ } & $\begin{array}{l}\mathrm{K} \text { and/or } \\
\mathrm{N} \text {-term }\end{array}$ & 144 & 6175 & 1 \\
\hline & $\mathrm{Y}$ & 144 & 318 & 1 \\
\hline & $S$ & 144 & 1 & 9 \\
\hline & $\mathrm{T}$ & 144 & 2 & 9 \\
\hline & C & 144 & 0 & 3 \\
\hline pyroglu & $\mathrm{N}$-term Q & -17 & 76 & 4 \\
\hline \multirow{2}{*}{ deamidation } & $\mathrm{N}$ & 1 & 345 & 5 \\
\hline & Q & 1 & 98 & 6 \\
\hline \multirow{2}{*}{ sodium adduct } & C-term & 22 & 4 & 7 \\
\hline & DE & 22 & 17 & 7 \\
\hline \multirow{2}{*}{ potassium adduct } & C-term & 38 & 5 & 8 \\
\hline & $\mathrm{DE}$ & 38 & 47 & 8 \\
\hline \multirow{9}{*}{ oxidation } & $M$ & 16 & 118 & 1 \\
\hline & $M$ & 32 & 7 & 10 \\
\hline & C & 16 & 1 & 10 \\
\hline & C & 32 & 12 & 10 \\
\hline & C & 48 & 2 & 10 \\
\hline & $P$ & 16 & 34 & 16 \\
\hline & $\mathrm{F}$ & 16 & 11 & 20 \\
\hline & $\mathrm{H}$ & 16 & 7 & 21 \\
\hline & W & 16 & 1 & 22 \\
\hline \multirow{8}{*}{ methylation } & $\mathrm{K}$ & 14 & 11 & 12 \\
\hline & K & 28 & 21 & 12 \\
\hline & $\mathrm{R}$ & 14 & 11 & 15 \\
\hline & $\mathrm{R}$ & 28 & 15 & 15 \\
\hline & $\mathrm{H}$ & 14 & 13 & 13 \\
\hline & $\mathrm{DE}$ & 14 & 69 & 14 \\
\hline & $\mathrm{NQ}$ & 15 & 23 & 17 \\
\hline & C & 14 & 5 & 19 \\
\hline \begin{tabular}{|l} 
trimethylation or \\
acetylation
\end{tabular} & $\mathrm{K}$ & 42 & 18 & 11 \\
\hline
\end{tabular}


Table 2. Summary of amino acid modifications found for Datasets 2-4. Each unique peptide sequence was counted only once, where the same sequence modified in 2 different ways would count as 2 sequences. Supplementary Table 2 lists the parameters used in each search specified.

\begin{tabular}{|l|c|c|c|c|c|c|}
\hline Putative & Amino & Delta & \multicolumn{3}{|c|}{ \# Unique Sequences } & Results from \\
Modification & Acid & Mass (Da) & Biofilm & Air & $\mathbf{O}_{2}$ & Search \# \\
\hline & K and/or & 144 & 4573 & 2745 & 610 & 1 \\
& N-term & & & & & \\
\hline iTRAQ & $\mathrm{Y}$ & 144 & 55 & 29 & 13 & 1 \\
\hline oxidation & $\mathrm{M}$ & 16 & 567 & 168 & 35 & 1 \\
\hline & $\mathrm{P}$ & 16 & 75 & 55 & 30 & 16 \\
\hline & $\mathrm{K}$ & 14 & 10 & 5 & 3 & 12 \\
methylation & $\mathrm{K}$ & 28 & 28 & 33 & 6 & 12 \\
\hline trimethylation & $\mathrm{DE}$ & 14 & 57 & 80 & 25 & 14 \\
\hline or acetylation & $\mathrm{K}$ & 42 & 16 & 9 & 5 & 11 \\
\hline
\end{tabular}

Table 3. Specific sequences found modified with $\mathrm{K}(+42)$ in multiple samples passing manual inspection.

\begin{tabular}{|c|l|c|c|}
\hline Protein & Sequence & Sample & Score \\
\hline ApsB & SADSIMWTVK(+42)FR & biofilm & $8.30 \mathrm{E}-03$ \\
adenylylsulphate reductase $\beta$ & & nitrate & $7.70 \mathrm{E}-03$ \\
DVU0846 & & $\mathrm{O}_{2}$ & $1.50 \mathrm{E}-03$ \\
\hline ApsA & DGYGPVGAWFLLFK(+42)AK & air & $5.50 \mathrm{E}-09$ \\
adenylylsulphate reductase $\alpha$ & & biofilm & $6.70 \mathrm{E}-09$ \\
DVU0847 & & nitrate & $6.70 \mathrm{E}-09$ \\
& & $\mathrm{O}_{2}$ & $1.60 \mathrm{E}-08$ \\
\hline Sat & VILSGTK(+42)LR & air & $7.20 \mathrm{E}-04$ \\
sulfate adenylyltransferase & & & \\
DVU1295 & & nitrate & $4.70 \mathrm{E}-04$ \\
\hline & & air & $7.10 \mathrm{E}-05$ \\
DsrC & bSEGISDISPDHQK(+42)IIDFLQDYYK & biofilm & $3.70 \mathrm{E}-04$ \\
dissimilatory sulfite & & nitrate & $2.30 \mathrm{E}-06$ \\
reductase $\gamma$ & LK(+42)EVYELFPSGPGK & biofilm & $4.00 \mathrm{E}-04$ \\
DVU2776 & & nitrate & $7.50 \mathrm{E}-04$ \\
& & $\mathrm{O}_{2}$ & $2.20 \mathrm{E}-04$ \\
\hline RplK & TMEQK(+42)GMITPVVITVYADR & biofilm & $2.70 \mathrm{E}-08$ \\
ribosomal protein L11 & & nitrate & $4.70 \mathrm{E}-07$ \\
\hline DVU2924 & & &
\end{tabular}




\section{TABLE OF CONTENTS SYNOPSIS AND GRAPHIC}

Several proteomic mass spectrometric datasets were acquired using orthogonal LC/MS/MS workflows in the sulfate-reducing organism, Desulfovibrio vulgaris Hildenborough. These datasets were mined for post translational modifications, leading to the discovery of many modified peptides. Several peptides contained acetylated or trimethylated lysine residues in proteins belonging to the sulfate reduction pathway (SRP). The SRP is encoded by genes unique to sulfate reducing bacteria, where sulfate serves as the primary electron acceptor.

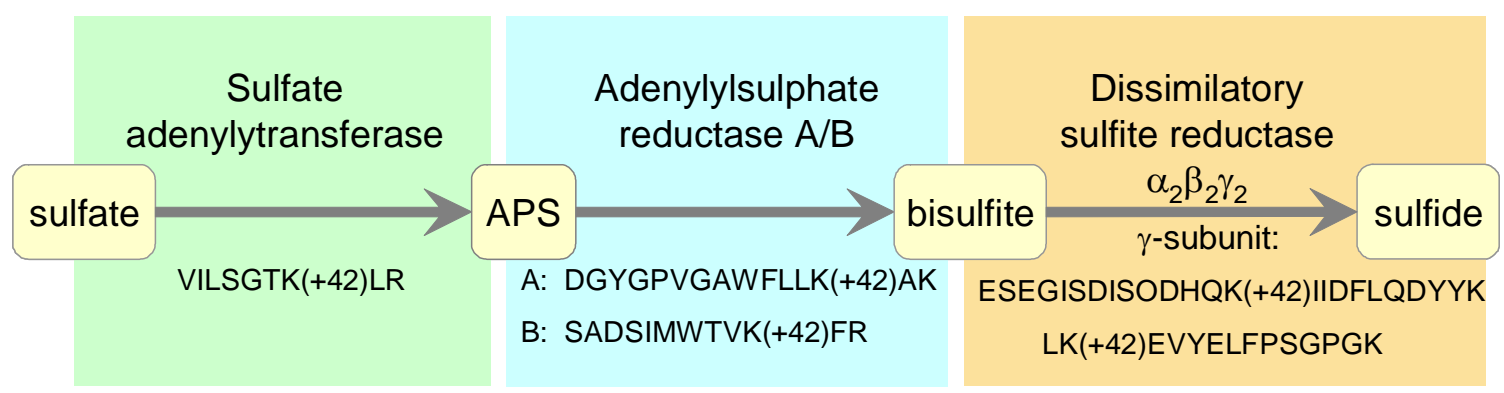

